\title{
Offshore oceanic impacts from the BP oil spill
}

To the Editor - Offshore drilling is a direct result of the growing global appetite for oil and gas. At present, ecosystems in the Gulf of Mexico are being exposed to an oil spill larger in magnitude and scope than any previous spill. Deepwater Horizon an ultra-deepwater drilling platform that BP leased from the drilling company Transocean - was completing a new well in the 1,600-m-deep Mississippi Canyon area when a giant bubble of methane caused an explosion and fire that sank the rig and claimed 11 lives. Since then, substantial quantities of oil and gas have leaked from the damaged wellhead into the deep ocean. The US government's present estimate of the leak rate is 20 to 40 thousand barrels of oil per day. At a gas-to-oil ratio of 3.5, this rate of leakage amounts to between $6.6 \times 10^{5}$ and $1.2 \times 10^{6} \mathrm{~kg}$ of gas released per day. Coastal impacts are being widely discussed. Here we draw attention to the unprecedented impact expected in the mid-depth and deep ocean.

This April's events contrast markedly with earlier massive spills in the US, such as the Exxon Valdez accident in $1989^{1}$ and the Santa Barbara spill in $1969^{2}$, both of which released oil directly into the near-surface ocean. The resultant slicks were mainly influenced by surface winds and currents, and much of the oil was either washed up on beaches - 40\% for the Exxon Valdez - or removed with skimmers. The 1978 Ixtoc oil spill in the Gulf of Mexico was caused by a blowout at the seafloor ${ }^{3}$. Although the blowout only occurred at a depth of $70 \mathrm{~m}$, it continued for nine months. Controlling the BP blowout - which is located at a depth of $1,667 \mathrm{~m}$ and around $80 \mathrm{~km}$ from the coast is likely to take much longer.

Initial concerns regarding the BP spill have focused on the coast. The need to protect critical coastal ecosystems and the coastal economy - which depends heavily on tourism and fisheries, as well as oil - is a valid concern. Indeed, experience gained during the Exxon Valdez spill indicates that large-scale spills can cause persistent negative effects on coastal wildlife that last for decades ${ }^{4}$. However, offshore oceanic impacts are less well understood.

The BP oil spill is introducing oil and methane gas into the deep water of the Gulf of Mexico. Previous studies on deepwater

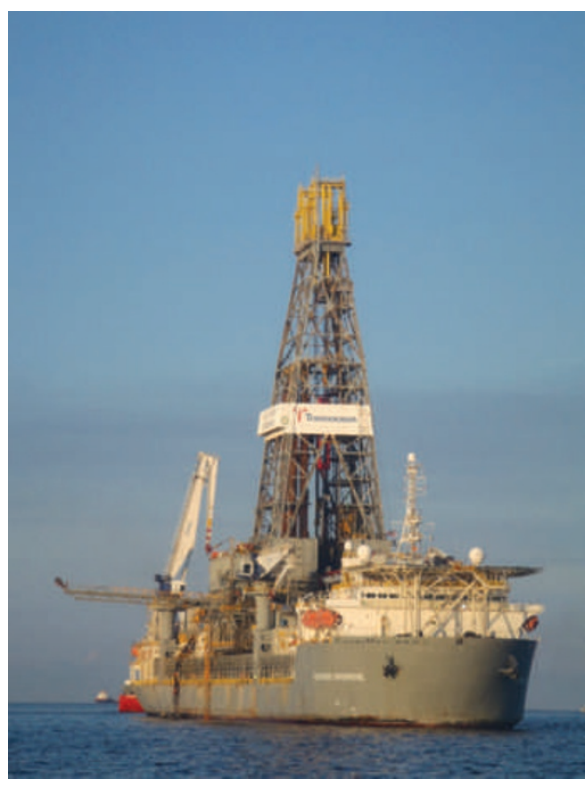

Figure 1| The Discoverer Enterprise ship, which has been siphoning off some of the leaking oil from the sea floor.

drilling leaks suggest that much of the oil becomes suspended in diffuse mid-depth plumes ${ }^{5,6}$. Mid-depth oil and gas will flow along the path of prevailing ocean currents. Tracing the transport of surface oil in two dimensions is highly complex; tracking and predicting movement of mid-depth plumes in three dimensions will be even more challenging.

The ultimate fate of mid-depth oil and gas is likely to differ from that of surface oil. Sunlight degrades oil in surface slicks, converting it into compounds that may or may not be susceptible to microbial uptake $^{7}$. Some of the oil will evaporate ${ }^{8}$. But neither of these processes operates in the mid ocean. Here, oil is likely to be removed by microbially mediated oxidation, or by sedimentation on the seabed. Whereas methane released close to the surface is likely to escape to the atmosphere, methane released at depth will probably be oxidized by microbes.

Microbially mediated consumption of oil and methane will lead to oxygen depletion. Oxygen depletion of bottom waters is a potentially significant concern, because deepwater oxygen is not replenished in situ by photosynthesis, as it is in surface waters, but by intermittent mixing with water originating from the surface. Bottom-water hypoxia and anoxia could result in shifts in microbialcommunity composition and the associated processes they mediate; the exclusion of oxygen-dependent components of the food web (including zooplankton, gelatinous zooplankton, fish, squid, and so on); and altered nutrient cycles.

Also at risk are seafloor benthic communities. The sea floor in the vicinity of natural oil and gas seeps is home to diverse chemosynthetic ecosystems and colonies of cold-water corals. Although these organisms have a high tolerance for reduced oxygen concentrations and hydrocarbons, the impacts of the BP spill will challenge the tolerance of sessile communities beyond any previous insult.

To identify and evaluate potential seafloor and mid-ocean impacts, it will be essential to launch a comprehensive monitoring programme to quantify and track the mass and breakdown of oil and gas in deep and mid-depth water, and to monitor oxygen dynamics closely in the coming weeks, months and years.

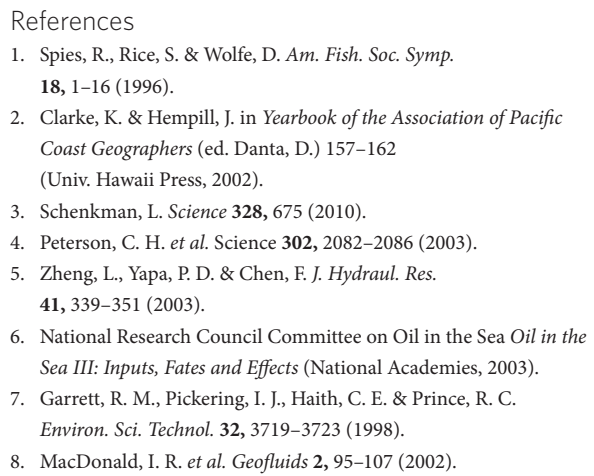

6. National Research Council Committee on Oil in the Sea Oil in the Sea III: Inputs, Fates and Effects (National Academies, 2003).

7. Garrett, R. M., Pickering, I. J., Haith, C. E. \& Prince, R. C.

Environ. Sci. Technol. 32, 3719-3723 (1998).

8. MacDonald, I. R. et al. Geofluids 2, 95-107 (2002)

\section{Samantha Joye ${ }^{1}$ and lan MacDonald ${ }^{2}$}

'Department of Marine Sciences, University of Georgia, Athens, Georgia 30602-3636, USA, ${ }^{2}$ Department of Oceanography, Florida State University, PO Box 3064326, Tallahassee,

Florida 32306, USA.

e-mail: mjoye@uga.edu; imacdonald@fsu.edu 